\title{
ORIENTATION EFFECTS IN TWO-PHASE MICROGAP FLOW
}

\author{
Franklin L. Robinson \\ Aerospace Engineer \\ Thermal Engineering Branch \\ NASA Goddard Space Flight Center \\ Greenbelt, MD 20771 \\ franklin.I.robinson@nasa.gov
}

\author{
Avram Bar-Cohen \\ Distinguished University Professor \\ Department of Mechanical Engineering \\ University of Maryland \\ College Park, MD 20742 \\ abc@umd.edu
}

\begin{abstract}
The high power density of emerging electronic devices is driving the transition from remote cooling, which relies on conduction and spreading, to embedded cooling, which extracts dissipated heat on-site. Two-phase microgap coolers employ the forced flow of dielectric fluids undergoing phase change in a heated channel within or between devices. Such coolers must work reliably in all orientations for a variety of applications (e.g., vehicle-based equipment), as well as in microgravity and high-g for other applications (e.g., spacecraft and aircraft). The lack of acceptable models and correlations for orientation- and gravityindependent operation has limited the use of two-phase coolers in such applications. Previous research has revealed that gravitational acceleration plays a diminishing role in establishing flow regimes and transport rates as the channel size shrinks, but there is considerable variation among the proposed microscale criteria and limited research on two-phase flows in low aspect ratio microgap channels. Reliable criteria for achieving orientation- and gravity-independent flow boiling would enable emerging systems to exploit this thermal management technique and streamline the technology development process.

As a first step toward understanding the effect of gravity on two-phase microgap flow and transport, in the present effort the authors have studied the effect of evaporator orientation and mass flux on near-saturated flow boiling of HFE7100 in a 1.01 $\mathrm{mm}$ tall by $13.0 \mathrm{~mm}$ wide by $12.7 \mathrm{~mm}$ long microgap channel. Orientation-independence, defined as achieving similar critical heat fluxes, heat transfer coefficients, and flow regimes across evaporator orientations, was achieved for mass fluxes of 400 $\mathrm{kg} / \mathrm{m}^{2}$-s and greater. The present results are compared to published criteria for achieving gravity-independence.
\end{abstract}

\section{INTRODUCTION AND MOTIVATION}

Increasing functionality and miniaturization of electronic components has exposed the limitations of the existing remote cooling paradigm, which relies on conduction and spreading across multiple interfaces to dissipate waste heat. The large temperature gradient between the heat source and sink that results from remote cooling has resulted in electronic systems that are thermally limited [1-4]. Embedded cooling overcomes these limitations by facilitating contact between the heat-generating device and coolant flow. Systems designed such that the coolant undergoes phase change provide additional benefits, such as higher heat transfer coefficients, smaller temperature gradients, hot spot mitigation, and lower pumping power.

Many ground and space systems may benefit from embedded cooling, including power electronics, lidar and radar systems, power generation systems, and nascent three-dimensional integrated circuits. The NASA Technology Roadmaps [5] list needs for removal of heat fluxes greater than $1 \mathrm{MW} / \mathrm{m}^{2}$ over small areas with tight temperature control; surfaces with micro- and nano-scale features to enhance two-phase heat transfer; and high-capacity, two-phase heat transport systems. A key benefit of embedded two-phase coolers for space missions is the ability to deliver waste heat from the heat source to the radiator with little temperature drop, which enables the radiator to operate at higher temperatures, thereby reducing its size and mass. Other benefits of pumped fluid loops include longer transport distances with potential use of multiple evaporators and condensers and precise flow rate control, which increases heat flux limits and enables on-demand shutdown of the cooling system [6].

One of the significant barriers to the use of two-phase coolers is the complex nature of convective boiling, particularly for microgravity and high-g applications for which only limited experimental data are available. The complexity can be reduced through the use of a single, low aspect ratio channel (i.e., a microgap) rather than an array of parallel microchannels. This configuration mitigates flow instabilities and reversals as generated vapor can expand both spanwise and downstream [7]. However, two-phase microgap coolers are not employed for 
spacecraft thermal management due to the lack of data for microgravity and high-g environments and absence of acceptable models that would enable extrapolation of heat transfer and flow behavior from available terrestrial data.

Physics-based flow regime maps reveal that gravitational acceleration plays a diminishing role in establishing flow regimes and transport rates as the channel size shrinks, thus facilitating more reliable extrapolation from existing databases. The goal of the present effort is to characterize the fluid physics governing two-phase flows in heated microgaps, with emphasis on methods for minimizing the effect of gravity in such flows. Experimental validation of orientation- and gravity-independent behavior would enable emerging systems to exploit this powerful thermal management technique and reduce development time and costs through reliance on ground-based testing.

\section{PREVIOUS RESEARCH}

\section{Microscale Definitions}

Microscale in the two-phase flow sense refers to flows for which the controlling mechanisms differ from those at the macroscale, with the influence of surface tension and shear forces increasing and that of gravity diminishing [8]. Many criteria that quantify the macroscale-to-microscale transition relate to the ratio between gravitational and surface tension forces. These criteria are often provided as threshold Bond numbers - or can be re-arranged to provide equivalent Bond numbers-below which the effect of gravity is expected to be small. The Bond number is commonly defined as

$$
B o_{D_{h}}=\frac{\left(\rho_{l}-\rho_{v}\right) \cdot g \cdot D_{h}^{2}}{\sigma}
$$

where $B o_{D_{h}}$ is the Bond number based on the hydraulic diameter, $\rho_{l}$ is the liquid density, $\rho_{v}$ is the vapor density, $g$ is the acceleration due to gravity, $D_{h}$ is the hydraulic diameter, and $\sigma$ is the surface tension. Ullman and Brauner [9] and Baldassari and Marengo [10] noted that this formulation of the Bond number might not represent correctly the relative significance of the gravitational and surface tension forces. For rectangular ducts configured with their width and length normal to the gravity vector, the Bond number becomes

$$
B o_{H W}=\frac{\left(\rho_{l}-\rho_{v}\right) \cdot g \cdot H \cdot W}{\sigma}
$$

where $B o_{H W}$ is the Bond number based on the channel height and width, $H$ is the channel height, and $W$ is the channel width. This variation of the Bond number accounts for the gravity term scaling with channel height $(\Delta \rho \cdot g \cdot H)$ and the surface tension term scaling with channel width $(\sigma / W)$. This formulation suggests that channels with low aspect ratios are more gravity dominated than implied by their hydraulic diameter [9]. This observation deserves additional attention, particularly considering that the liquid-vapor interface rarely spans the channel width in low aspect ratio channels at practical flow rates for cooling applications. A more appropriate formulation of the surface tension term in the Bond number may consider the widest liquid-vapor interface rather than the channel width. Another consideration related to the Bond number is the selection of the length scale for the gravity term. For a rectangular channel, the gravity vector can be parallel to the channel height, width, or length, depending on the channel orientation, resulting in a wide range of Bond numbers for the same channel operated in different orientations.

In addition to the Bond number, the Weber and Froude numbers are often used to characterize two-phase flows, with the Weber number scaling inertia and surface tension forces and the Froude number scaling inertia and gravity forces. The Weber number is defined as

$$
W e=\frac{\rho_{m} \cdot U_{m}^{2} \cdot L}{\sigma}=\frac{G^{2} \cdot L}{\rho_{m} \cdot \sigma}
$$

where $\rho_{m}$ is the mixture density, $U_{m}$ is the mixture velocity, $L$ is the characteristic length, and $G$ is the mass flux. The characteristic length is the channel diameter for circular ducts and the larger of the channel width and channel height for rectangular ducts. The Froude number is defined below.

$$
F r=\sqrt{\frac{W e}{B o}}=\frac{G}{\sqrt{\rho_{m} \cdot\left(\rho_{l}-\rho_{v}\right) \cdot g \cdot L}}
$$

The characteristic length for the Froude number should be the channel dimension parallel to the gravity vector, although the hydraulic diameter is sometimes used.

\section{Orientation Effects in Flow Boiling}

Many experiments have been performed to assess the effect of evaporator orientation on flow boiling performance, with some experiments also being performed in reduced gravity. In the results presented below, the Bond number is calculated using the hydraulic diameter and, for rectangular ducts, the channel height and width in the horizontal, upward facing heater orientation (subsequently referred to as the HU orientation). The previous efforts are sorted loosely in order of decreasing Bond number. For simplicity, the Weber and Froude numbers are calculated using only the hydraulic diameter and saturated liquid properties (i.e., the effect of vapor quality is not included).

Zhang, Mudawar, and Hasan [11] studied near-saturated flow boiling $\left(\Delta T_{\text {sub }}=3-4 \mathrm{~K}\right)$ of FC72 in a $5.0 \mathrm{~mm}$ tall by 2.5 $\mathrm{mm}$ wide by $101.6 \mathrm{~mm}$ long channel $\left(D_{h}=3.33 \mathrm{~mm} ; B o_{D_{h}} \cong\right.$ $\left.17.8 ; B o_{H W} \cong 20.0\right)$. At $0.1 \mathrm{~m} / \mathrm{s}(W e \cong 5.5 ; F r \cong 0.6)$, critical heat flux (CHF) and flow regimes varied considerably with orientation (range of 36 to $\left.276 \mathrm{~kW} / \mathrm{m}^{2}\right)$, but at $1.5 \mathrm{~m} / \mathrm{s}(W e \cong 1238 ; \mathrm{Fr} \cong$ 8.1) large drag forces reduced orientation effects (range of 225 to $310 \mathrm{~kW} / \mathrm{m}^{2}$ ). In microgravity, unlike in terrestrial gravity, $\mathrm{CHF}$ followed the same mechanism at low and high velocities; at 0.25 and $1.4 \mathrm{~m} / \mathrm{s}$, bubbles coalesced along the heated wall into

This material is declared a work of the U.S. Government and is not subject to copyright protection in the United States. Approved for public release; distribution is unlimited. 
large vapor patches. However, this behavior did not translate to similar CHF, which doubled from 140 to $280 \mathrm{~kW} / \mathrm{m}^{2}$ as the velocity increased. Little variation in CHF was found across the same velocity range for the HU orientation in terrestrial gravity.

Konishi, Mudawar, and Hasan [12] studied flow boiling of FC72 in a $5.0 \mathrm{~mm}$ tall by $2.5 \mathrm{~mm}$ wide by $101.6 \mathrm{~mm}$ long channel with two-phase inlet $\left(D_{h}=3.33 \mathrm{~mm} ; B o_{D_{h}} \cong 18.2 ; B o_{H W} \cong\right.$ 20.5). They performed studies at eight evaporator orientations with liquid inlet velocities from 0.126 to $1.130 \mathrm{~m} / \mathrm{s}$ ( $W e \cong 8.9-$ $718 ; \mathrm{Fr} \cong 0.7-6.3$ ) and inlet vapor qualities of 0.01 to 0.19 . $\mathrm{CHF}$ varied significantly with orientation and velocity, with the highest values achieved when $\theta=0^{\circ}$ or $45^{\circ}$ and the lowest values achieved when $\theta=180^{\circ}$ or $225^{\circ}$. Variation in $\mathrm{CHF}$ with respect to orientation diminished as the inlet velocity and quality increased.

Kharangate, Konishi, and Mudawar [13] studied near saturated $\left(\Delta T_{\text {sub }}=2-8 \mathrm{~K}\right)$ flow boiling of FC72 in a $5.0 \mathrm{~mm}$ tall by $2.5 \mathrm{~mm}$ wide by $114.6 \mathrm{~mm}$ long channel $\left(D_{h}=3.33 \mathrm{~mm} ; B o_{D_{h}} \cong\right.$ $\left.18.1 ; B o_{H W} \cong 20.3\right)$. They performed studies at different evaporator orientations and in reduced gravity during parabolic flights over a range of flow rates $(W e \cong 6.8-2277 ; F r \cong 0.6-11.2)$. The authors found that the horizontal heater up and vertical upflow orientations provided the upper CHF bound, the horizontal heater down and vertical downflow orientations provided the lower $\mathrm{CHF}$ bound, and that the difference in CHF among the orientations was less pronounced as the liquid inlet velocity increased (especially above $1.5 \mathrm{~m} / \mathrm{s}$ ).

Wang et al. [14] studied the effect of inclination on flow boiling of HFE7100 in a copper heat sink with seven channels, each $0.520 \mathrm{~mm}$ tall by $2.005 \mathrm{~mm}$ wide by $25.4 \mathrm{~mm}$ long $\left(D_{h}=0.826 \mathrm{~mm} ; B o_{D_{h}}=1.06 ; B o_{H W}=1.63\right)$. The evaporator was configured with angles $(\theta)$ of $-90^{\circ}$ (vertical downflow), $-45^{\circ}, 0^{\circ}$ (horizontal), $45^{\circ}$, and $90^{\circ}$ (vertical upflow). Vertical downflow provided the lowest heat transfer coefficient (HTC) at each of the mass and heat fluxes studied (100, 200, and $300 \mathrm{~kg} / \mathrm{m}^{2}-\mathrm{s} ; 25$ and $37.5 \mathrm{~kW} / \mathrm{m}^{2}$ ). The $45^{\circ}$ inclined orientation provided the best heat transfer at mass fluxes of 100 and 200 $\mathrm{kg} / \mathrm{m}^{2}-\mathrm{s}(W e \cong 0.5-2.1 ; F r \cong 0.7-1.4)$, which the authors attributed to the combined effect of buoyancy and asymmetry of the elongated bubbles. At $300 \mathrm{~kg} / \mathrm{m}^{2}$-s $(W e \cong 4.8 ; F r \cong 2.1)$, the heat transfer performance was less dependent on orientation, which the authors attributed to the higher Froude number. Higher Froude numbers also resulted in bubbles that were more symmetric, even for inclined orientations.

Lee et al. [15] studied orientation effects on subcooled flow boiling $\left(\Delta T_{\text {sub }}=10-16 \mathrm{~K}\right)$ of FC72 in an array of four parallel sets of 20 channels, each $1.0 \mathrm{~mm}$ deep by $0.231 \mathrm{~mm}$ wide by $152.4 \mathrm{~mm}$ long $\left(D_{h}=0.375 \mathrm{~mm} ; B o_{D_{h}} \cong 0.34 ; B o_{H W} \cong 0.55\right)$. Two-phase HTCs varied significantly with orientation at mass fluxes of 180 to $302 \mathrm{~kg} / \mathrm{m}^{2}$-s $(W e \cong 1.3-3.6 ; \mathrm{Fr} \cong 2.0-7.0)$, but good agreement was observed across orientations for mass fluxes of 358 to $645 \mathrm{~kg} / \mathrm{m}^{2}-\mathrm{s}(W e \cong 5.0-16.4 ; \mathrm{Fr} \cong 3.9-7.0)$.

Zhang, Pinjala, and Wong [16] studied the effect of evaporator orientation on subcooled $\left(\Delta T_{\text {sub }}=31 \mathrm{~K}\right)$ flow boiling of FC72 in an array of twenty-one $2.0 \mathrm{~mm}$ tall by $0.2 \mathrm{~mm}$ wide by $15 \mathrm{~mm}$ long channels $\left(D_{h}=0.364 \mathrm{~mm} ; B o_{D_{h}} \cong 0.22 ; B o_{H W} \cong 0.66\right)$ at mass fluxes of 130,228 , and $314 \mathrm{~kg} / \mathrm{m}^{2}$-s $(W e \cong 0.4-2.4 ; F r \cong$ $1.4-3.3)$. In the vertical downflow orientation at the lowest mass flux, bubbles moved at a much lower velocity $(3-18 \mathrm{~mm} / \mathrm{s})$ than the bulk liquid $(75 \mathrm{~mm} / \mathrm{s})$, but the average thermal resistance of the heat sink was only $4 \%$ higher than that achieved in the vertical upflow orientation. At higher mass fluxes, the variation across orientations was negligible.

Leão et al. [17] studied slightly subcooled $\left(\Delta T_{\text {sub }}=5-10 \mathrm{~K}\right)$ flow boiling of R245fa in a copper heat sink with 50 parallel channels, each $0.494 \mathrm{~mm}$ tall by $0.123 \mathrm{~mm}$ wide by $15 \mathrm{~mm}$ long $\left(D_{h}=0.197 \mathrm{~mm} ; B o_{D_{h}}=0.039 ; B o_{H W}=0.060\right)$. They covered mass fluxes of 300 to $900 \mathrm{~kg} / \mathrm{m}^{2}-\mathrm{s}(W e \cong 1.0-9.3 ; \mathrm{Fr} \cong 5.2-$ 15.5) and heat fluxes up to $300 \mathrm{~kW} / \mathrm{m}^{2}$. They found that the horizontal position provided the highest average HTC. The flow distribution was uniform in the vertical upflow orientation, with only rare instances of reverse flow. The non-uniformity of the two-phase flow distribution among the channels was worst with the heat sink vertically positioned with microchannels horizontally aligned; the maldistribution was less severe with higher mass fluxes, more subcooling, and lower heat fluxes.

Kandlikar and Balasubramanian [18] studied flow boiling of water in an array of six parallel channels; each channel was 0.197 $\mathrm{mm}$ deep by $1.054 \mathrm{~mm}$ wide by $63.5 \mathrm{~mm}$ long $\left(D_{h}=\right.$ $\left.0.332 \mathrm{~mm} ; B o_{D_{h}} \cong 0.018 ; B o_{H W} \cong 0.033\right)$. They collected data at a single mass flux of $120 \mathrm{~kg} / \mathrm{m}^{2}-\mathrm{s}(W e \cong 4.1 ; \mathrm{Fr} \cong 15.3)$ and a single heat flux of $317 \mathrm{~kW} / \mathrm{m}^{2}$ in three orientations (horizontal, vertical upflow, and vertical downflow). The horizontal and vertical upflow orientations provided similar HTCs, but the HTC in the vertical downflow orientation was $26 \%$ less, which the authors attributed to severe backflow and corresponding flow maldistribution in the vertical downflow orientation. The authors speculated that the absence of gravity would yield results similar to those of the horizontal orientation since the absence of gravity would not cause any changes in the forces along the flow direction relative to this orientation.

In a study of the dynamic motion of liquid-vapor systems in low gravity, Reynolds, Saad, and Satterlee [19] categorized twophase systems into regimes based on the dominance of surface tension, inertia, and gravity based on values of the Bond, Weber, and Froude numbers. They proposed that the boundaries among the regimes occurred when the non-dimensional parameters were near unity, with surface tension dominating when $B o \ll 1$ and $W e \ll 1$, gravity dominating when $B o \gg 1$ and $F r \ll 1$, and inertia dominating when $B o \gg 1$ and $F r \gg 1$.

Baba et al. [20] studied subcooled $\left(\Delta T_{\text {sub }}=32-33 \mathrm{~K}\right)$ flow boiling of FC72 in circular tubes with inner diameters of 0.13 $\mathrm{mm}(B o=0.033)$ and $0.51 \mathrm{~mm}(B o=0.51)$. The $0.13 \mathrm{~mm}$ diameter tube was $100 \mathrm{~mm}$ long and the $0.51 \mathrm{~mm}$ diameter tube was $200 \mathrm{~mm}$ long. Experiments were performed in horizontal, vertical upflow, and vertical downflow orientations covering mass fluxes of 50 to $200 \mathrm{~kg} / \mathrm{m}^{2}$-s and heat fluxes of 2.6 to $16.4 \mathrm{~kW} / \mathrm{m}^{2}$. They observed that HTCs were influenced by tube orientation when $\mathrm{Fr}<4$ in the $0.51 \mathrm{~mm}$ diameter tube. They also found that there was no effect of tube orientation for the $0.13 \mathrm{~mm}$ diameter 
tube for all mass and heat fluxes studied, and HTCs were independent of vapor quality when $W e<5$, which they interpreted as being the transition between surface tension and inertia dominated regimes.

Due to length constraints, additional studies are not covered here, but are covered in several review papers [10, 21-23].

Collectively, the results presented cover orientation effects in two-phase flows for rectangular channels with hydraulic diameters of 0.197 to $3.333 \mathrm{~mm}$ and Bond numbers based on the hydraulic diameter of 0.018 to 18.2 . In such channels, orientation effects are reduced or eliminated as the channel size decreases and as the velocity, subcooling, and vapor quality increase. Despite considerable research in this area, the channels in previous studies have been limited to aspect ratios $(H / W)$ in the range of 0.1 to 3.9 (microgaps tend to have aspect ratios $<0.1$ ) and dominant force maps have been developed exclusively based on results for circular ducts.

\section{OBJECTIVES}

The literature review revealed an absence of criteria for predicting the transition to orientation- and gravity-independent two-phase flow in microgap channels. The appropriate length scales used to calculate the relevant non-dimensional numbers for the microscale criteria also remain uncertain. These issues prevent the reliable use of existing criteria without further validation. Accordingly, a research effort was initiated to:

1. Explore orientation effects on flow boiling CHF, HTCs, and flow regimes in microgap channels;

2. Study the efficacy of using the Bond, Weber, and Froude numbers for establishing orientation- and gravity-independent behavior in microgap channels; and

3. Establish the magnitude of appropriate non-dimensional numbers for orientation-independent behavior.

As a first step in meeting these objectives, a test facility has been developed and preliminary experiments on the flow boiling performance of HFE7100 in a $1.01 \mathrm{~mm}$ tall by $13.0 \mathrm{~mm}$ wide microgap have been performed.

\section{EXPERIMENTAL METHODS}

\section{Flow Loop}

An experimental facility was assembled to provide twophase test data with the evaporator in various orientations with respect to the gravity vector. The flow loop, a schematic of which is shown in Figure 1, supplies degassed fluid to the evaporator at the prescribed flow rate, temperature, and pressure. A gear pump with an electromagnetic drive (Micropump Series GA) circulates the working fluid. A temperature-controlled in-line heater (Watlow Fluent FLC-16) provides the desired liquid subcooling at the evaporator inlet. Fluid leaving the evaporator is condensed and subcooled via a plate heat exchanger (Lytron LL520G14) connected to a refrigerated/heating circulator (Julabo FP50). The circulator working fluid is distilled water. A $7 \mu \mathrm{m}$ sintered metal filter collects particulate contamination within the flow loop. A temperature-controlled, two-phase reservoir regulates the low- side pressure for the loop and compensates for the expansion and contraction of the working fluid.

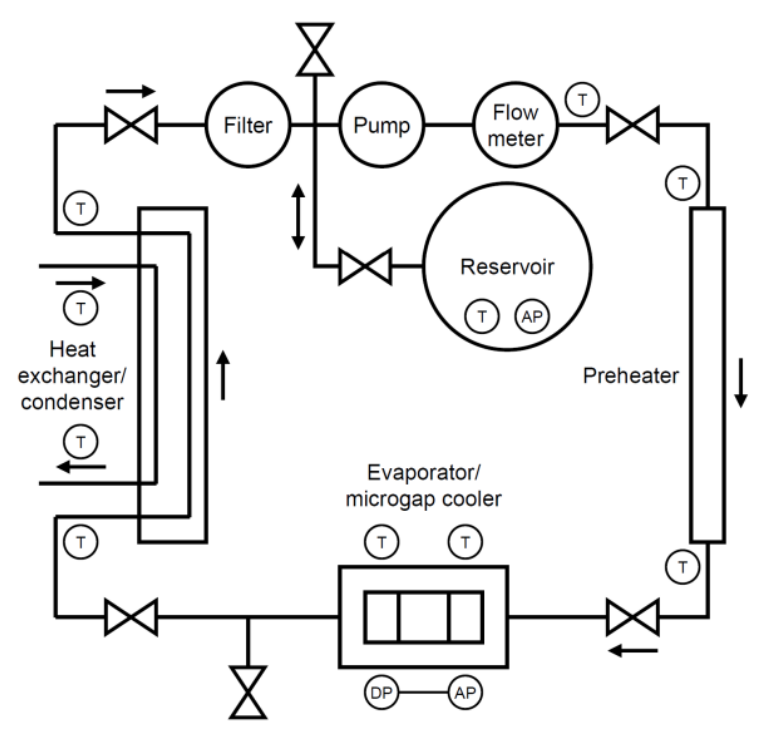

Figure 1: Flow loop schematic

The liquid flow rate is measured by a microturbine flow sensor with a range of 50 to $500 \mathrm{ml} / \mathrm{min}$ and accuracy of $\pm 0.5 \%$ of the full-scale range (McMillan Flow Products Model 104). The fluid temperature is measured via type-T thermocouple probes at the flow meter, preheater inlet and outlet, evaporator inlet and outlet, condenser inlet and outlet, and reservoir vapor space. The absolute pressure is measured in the reservoir vapor space and evaporator inlet by silicon, strain gauge type transducers with ranges of 0 to $300 \mathrm{kPa}$ and accuracies of $\pm 0.1 \%$ of the full scale range (Honeywell FP2000). A variable reluctance pressure sensor measures the differential pressure between the evaporator inlet and outlet manifolds with replaceable diaphragms, each with an accuracy of $\pm 0.25 \%$ of the full-scale range (Validyne Engineering DP15). For the present study, the differential pressure transducer was calibrated with a range of 0 to $1.5 \mathrm{kPa}$.

The working fluid is HFE7100, due to its saturation properties (boiling point of $59.8{ }^{\circ} \mathrm{C}$ at $101.3 \mathrm{kPa}$ ), low freezing point $\left(-135{ }^{\circ} \mathrm{C}\right)$, low electrical conductivity, non-toxicity, and nonflammability. The flow loop was designed to minimize the system leak rate due to concerns of air infiltrating the system, which would affect the thermodynamic properties and boiling performance of the fluid [24-26]. Prior to charging the loop, the working fluid was subjected to multiple freeze-pump-thaw cycles to remove non-condensable gases. The saturation pressure and temperature of the degassed fluid were measured and compared against reference data [27] to verify that the noncondensable gases had been removed.

\section{Evaporator Module}

The evaporator heat source is a $12.7 \mathrm{~mm}$ by $12.7 \mathrm{~mm}$ by 0.6 mm silicon thermal test chip (TTC) mounted to a printed circuit board (Thermal Engineering Associates TTV-4102). The TTC 
provides uniform heating with a four-wire heater circuit design to eliminate parasitic heat losses in the supply wiring. Ten diodes provide temperature measurements of the frontside of the TTC. The diodes were calibrated using a constant temperature air oven and four-wire, class $1 / 10 \mathrm{DIN}, 100 \Omega$ resistance temperature detector probes. The temperature of the oven was held constant until consecutive readings of the values of each temperature and resistance measurement, averaged at $1 \mathrm{~Hz}$ over 5 minutes, varied by less than $0.01{ }^{\circ} \mathrm{C} / \mathrm{min}$ and $0.1 \Omega / \mathrm{min}$, respectively. For flow loop operations, power to the TTC was supplied by a Keithley 2280S-60-3 programmable DC power supply.

The evaporator assembly, shown in Figure 2, is composed of a thermal isolator base, fluid enclosure base, thermal test vehicle, fluid enclosure, polycarbonate insert, fluid enclosure cap, and thermal isolator cap. The fluid enclosure includes the fluid inlet and outlet taps and manifolds, pressure taps for absolute and differential pressure measurements, and evaporator inlet and outlet fluid temperature probes. Replaceable, transparent polycarbonate inserts are inset to the fluid enclosure. The microgap channel is located between the exposed face of the TTC and the interior face of the polycarbonate cover. Measurements of the surfaces via confocal microscopy revealed an average roughness of $0.035 \mu \mathrm{m} \pm 0.018 \mu \mathrm{m}$ for the silicon TTC and $0.348 \mu \mathrm{m} \pm$ $0.018 \mu \mathrm{m}$ for the polycarbonate surface of the microgap. The process for characterizing the thermal losses of the evaporator assembly to ambient are detailed in [28].

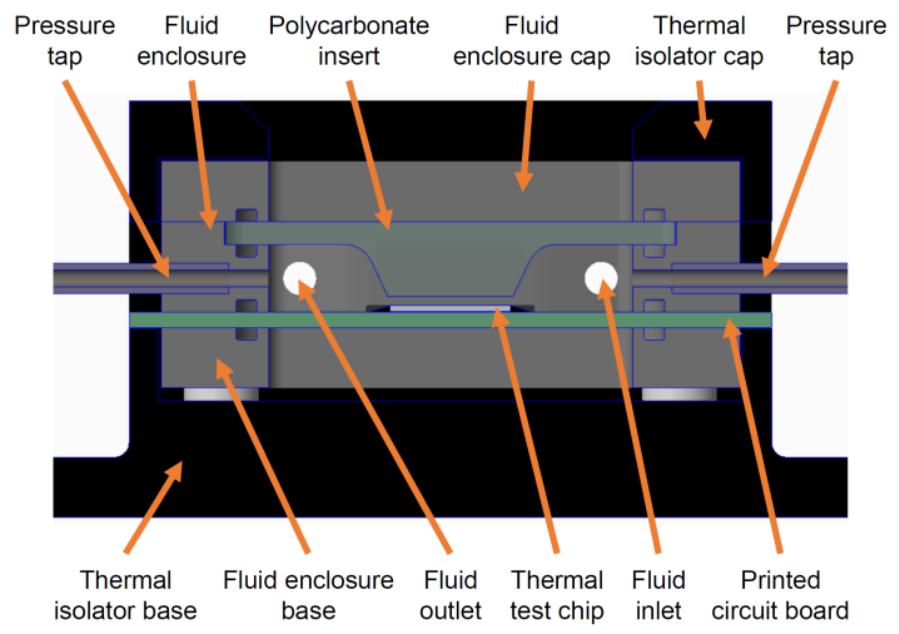

Figure 2: Evaporator assembly axial cross section (to scale; for reference, thermal test chip is $12.7 \mathrm{~mm}$ wide)

A Keyence VHX-5000 digital microscope with a precision stage was used to measure the gap height after the evaporator assembly was completed. The height of the stage was adjusted in $10 \mu \mathrm{m}$ increments until the top of the silicon TTC was in focus. Using this height as the zero reference, the height of the stage was then adjusted until the bottom of the polycarbonate cover was in focus to determine the microgap height. For the present assembly, seven measurements were taken, which produced an average gap height of $1.02 \mathrm{~mm}$, range of 0.99 to $1.04 \mathrm{~mm}$, and uncertainty of $\pm 0.019 \mathrm{~mm}$. The optical measurement technique was validated in an earlier effort [28] and the present measurements agree with the expected channel height based on individual component measurements, which produced an expected gap height of $1.03 \mathrm{~mm}$.

Optical measurements of the gap height were performed at $22{ }^{\circ} \mathrm{C}$ with the interior cavity of the flow enclosure open to atmospheric pressure. During two-phase testing, the flow enclosure and polycarbonate temperature was 55 to $60{ }^{\circ} \mathrm{C}$ based on a nominal inlet saturation temperature of $62^{\circ} \mathrm{C}$, inlet subcooling of 1 to $5{ }^{\circ} \mathrm{C}$, and convective losses to the ambient. The pressure effect on the microgap height was neglected, as the saturation pressure of $\mathrm{HFE} 7100$ at $62{ }^{\circ} \mathrm{C}$ is close to atmospheric pressure. Accounting for thermal expansion of the polycarbonate cover island and stainless steel enclosure up to the ledge on which the polycarbonate cover rests and assuming a temperature rise of $35^{\circ} \mathrm{C}$ results in an estimated reduction in the microgap height of $0.01 \mathrm{~mm}$. Thus, the in-situ gap height was $1.01 \mathrm{~mm}$.

\section{Uncertainty}

Voltage and current measurements for the TTC were read directly from power supply and recorded by the data acquisition program. All other signals were read by a National Instruments data acquisition chassis with modules for thermocouples, voltages, and resistances. The data acquisition rate was $25 \mathrm{~Hz}$. The uncertainties are listed in Table 1.

\section{Table 1: Measurement and derived value uncertainties}

\begin{tabular}{|l|c|c|}
\hline \multicolumn{1}{|c|}{$\begin{array}{c}\text { Measurement or } \\
\text { Derived Value }\end{array}$} & Absolute Uncertainty & $\begin{array}{c}\text { Normalized } \\
\text { Uncertainty }\end{array}$ \\
\hline Heat flux & $0.04-1.2 \mathrm{~kW} / \mathrm{m}^{2}$ & $0.4-0.6 \%$ \\
\hline Surface temperature & $0.33-0.37^{\circ} \mathrm{C}$ & $0.3-0.6 \%$ \\
\hline $\begin{array}{l}\text { Evaporator inlet liquid } \\
\text { temperature }\end{array}$ & $0.60^{\circ} \mathrm{C}$ & $1.1 \%$ \\
\hline $\begin{array}{l}\text { Evaporator inlet } \\
\text { saturation temperature }\end{array}$ & $0.08{ }^{\circ} \mathrm{C}$ & $0.1 \%$ \\
\hline $\begin{array}{l}\text { Single-phase heat } \\
\text { transfer coefficient }\end{array}$ & $0.03-0.13 \mathrm{~W} / \mathrm{m}^{2}-\mathrm{K}$ & $1.6-16.3 \%$ \\
\hline $\begin{array}{l}\text { Two-phase heat } \\
\text { transfer coefficient }\end{array}$ & $0.05-0.13 \mathrm{~W} / \mathrm{m}^{2}-\mathrm{K}$ & $1.4-2.2 \%$ \\
\hline Flow rate & $6.15 \mathrm{E}-5 \mathrm{~kg} / \mathrm{s}$ & $0.7-4.7 \%$ \\
\hline Mass flux & $5.0-14.0 \mathrm{~kg} / \mathrm{m}^{2}-\mathrm{s}$ & $2.0-5.0 \%$ \\
\hline
\end{tabular}

\section{Orientations and Bond Numbers}

In order to produce a range of gravity effects, the evaporator was configured in five orientations: horizontal heater up (HU), vertical upflow (VU), horizontal heater down (HD), vertical downflow (VD), and sideways (SW), as shown in Figure 3.

The appropriate length scales used in the calculation of the Bond number remain a subject of debate, as discussed in the "Microscale Definitions" section. Table 2 lists the Bond number for each orientation using two formulations:

1. Conventional definition of the hydraulic diameter, squared;

2. Channel width, $W$, for the surface tension term and length in the direction of the gravity vector (i.e., $H$ for the $\mathrm{HU}$ and

This material is declared a work of the U.S. Government and is not subject to copyright protection in the United States. Approved for public release; distribution is unlimited. 
HD orientations, $L$ for the VU and VD orientations, and $W$ for the SW orientation) for the gravity term.

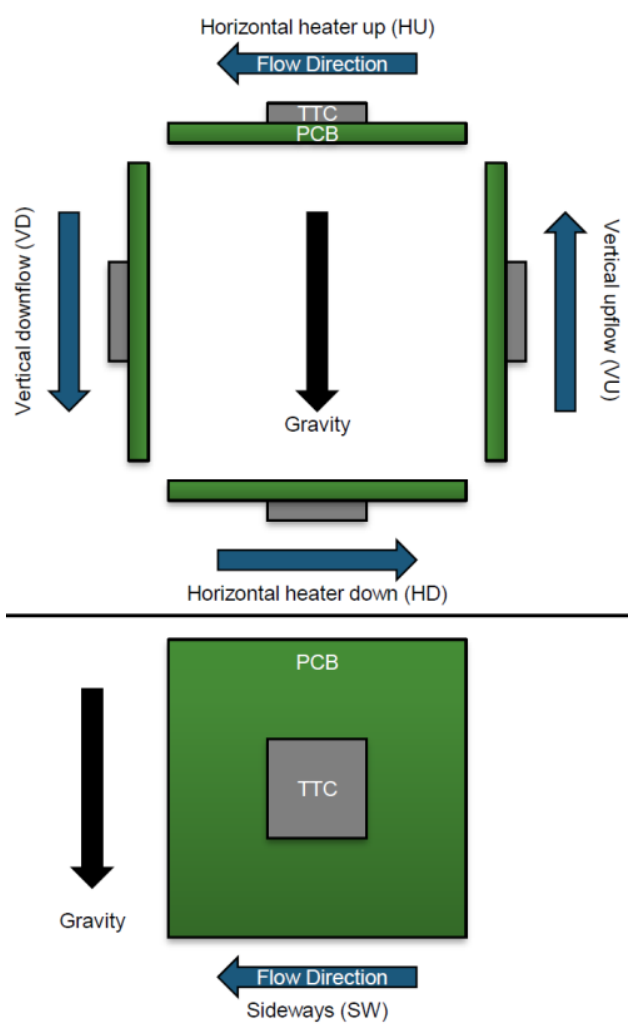

Figure 3: Evaporator orientations

Table 2: Bond number variation as a function of formulation and orientation for a fixed geometry

\begin{tabular}{|c|c|c|}
\hline Orientation & \multicolumn{2}{|c|}{ Bond Number } \\
\hline $\mathrm{HU}$ & \multirow{5}{*}{$\frac{\Delta \rho \cdot g \cdot D_{h}{ }^{2}}{\sigma}=4.9$} & $\Delta \rho \cdot g \cdot H \cdot W$ \\
\hline HD & & $\sigma$ \\
\hline VU & & $\Delta \rho \cdot g \cdot L \cdot W$ \\
\hline VD & & $\sigma$ \\
\hline SW & & $\frac{\Delta \rho \cdot g \cdot W \cdot W}{\sigma}=237$ \\
\hline
\end{tabular}

\section{Operating Sequence}

Conditioning the flow loop for data collection began with enabling the reservoir heater and allowing its temperature and pressure to stabilize. After that, the refrigerated/heating circulator was powered on, followed by powering on the flow loop pump and preheater. The pump control voltage, preheater power, and reservoir set point were adjusted to achieve the desired evaporator inlet conditions. Once stable, data was recorded for 60 seconds. Then, $10 \mathrm{~kW} / \mathrm{m}^{2}$ was applied to the TTC. Once stable, data was again recorded for 60 seconds. This process was continued until the onset of boiling, after which the pump control voltage, preheater power, and reservoir set point were adjusted to maintain the desired evaporator inlet conditions after each increase in the heat flux. Photos were captured at each heat flux after the onset of boiling. The heat flux was increased in increments of 10 to $20 \mathrm{~kW} / \mathrm{m}^{2}$, with data recorded for 60 seconds at each heat flux, until the user-specified temperature limit of 120 ${ }^{\circ} \mathrm{C}$ was violated.

\section{RESULTS AND ANALYSIS}

Single- and two-phase data were collected for five orientations at nominal mass fluxes of 100, 200, 300, 400, 600, and 700 $\mathrm{kg} / \mathrm{m}^{2}-\mathrm{s}$. The inlet saturation temperature was held constant at $62{ }^{\circ} \mathrm{C}$. The inlet subcooling was kept as low as possible without introducing vapor into the evaporator inlet manifold. At the lowest mass flux of $100 \mathrm{~kg} / \mathrm{m}^{2}-\mathrm{s}$, the inlet subcooling averaged $3.7^{\circ} \mathrm{C}$ and at the highest mass flux of $700 \mathrm{~kg} / \mathrm{m}^{2}-\mathrm{s}$, the inlet subcooling averaged $1.3{ }^{\circ} \mathrm{C}$. At $100 \mathrm{~kg} / \mathrm{m}^{2}-\mathrm{s}$, the minimum inlet quality was -0.063 and the maximum outlet quality was 0.088 ; at $700 \mathrm{~kg} / \mathrm{m}^{2}-\mathrm{s}$, the same range was -0.020 to 0.026 .

\section{Critical Heat Flux}

Figure 4 shows the flow boiling $\mathrm{CHF}$ as a function of mass flux and evaporator orientation. At $100 \mathrm{~kg} / \mathrm{m}^{2}-\mathrm{s}$, the orientation with the lowest CHF, vertical downflow, suffered from a $53 \%$ deterioration in $\mathrm{CHF}$ relative to the orientation with the highest $\mathrm{CHF}$, vertical upflow. The variation in $\mathrm{CHF}$ between the best and worst orientations decreased considerably as the mass flux increased to $200 \mathrm{~kg} / \mathrm{m}^{2}$-s $(18 \%), 300 \mathrm{~kg} / \mathrm{m}^{2}$-s $(10 \%), 400 \mathrm{~kg} / \mathrm{m}^{2}$ s $(5 \%), 600 \mathrm{~kg} / \mathrm{m}^{2}-\mathrm{s}(7 \%)$, and $700 \mathrm{~kg} / \mathrm{m}^{2}-\mathrm{s}(7 \%)$, which can be attributed to the more dominant role of inertia as the mass flux increases. Nonetheless, even at mass fluxes of $400 \mathrm{~kg} / \mathrm{m}^{2}-\mathrm{s}$ and greater, the variation in $\mathrm{CHF}$ across orientations exceeded the experimental uncertainty $(0.4 \%)$, indicating that a small gravity effect persisted. From 300 to $700 \mathrm{~kg} / \mathrm{m}^{2}$-s, CHF increases nearly linearly with mass flux, which is characteristic of nucleate boiling. Nucleate boiling is expected due to the very short channel length $\left(L / D_{h}=6.8\right)$ and low outlet qualities.

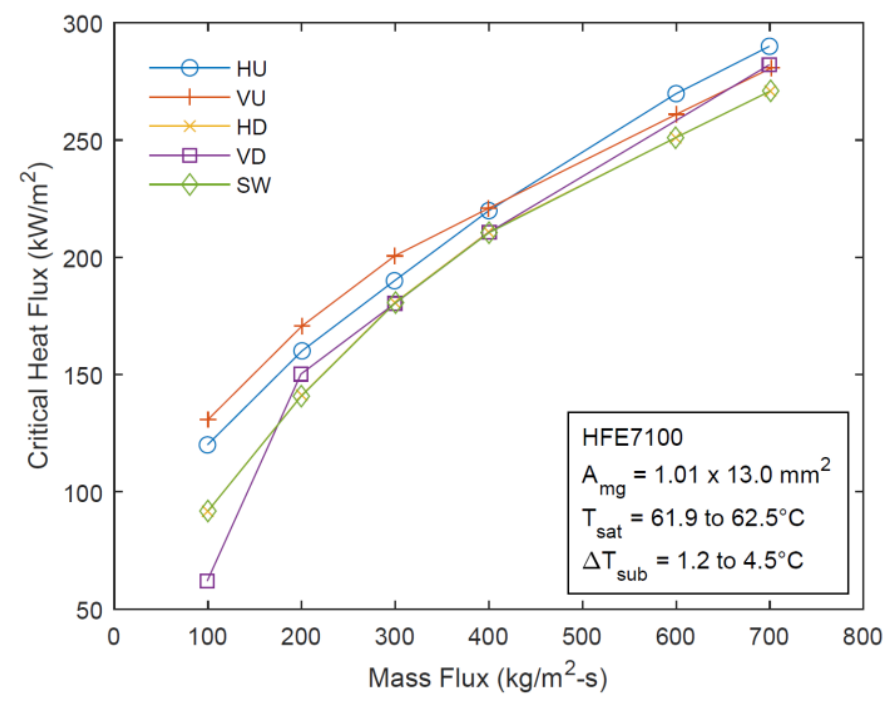

Figure 4: Flow boiling CHF as a function of mass flux and evaporator orientation

This material is declared a work of the U.S. Government and is not subject to copyright protection in the United States. Approved for public release; distribution is unlimited. 


\section{Heat Transfer Coefficients and Flow Regimes}

Figure 5 shows the average single- and two-phase HTCs as a function of heat flux, evaporator orientation, and mass flux. For all test cases, the HTCs are initially for single-phase liquid; the single-phase HTCs show excellent agreement across orientations, as expected. A jump in the HTC is observed at the onset of nucleate boiling (ONB). The largest increases in HTC were observed for cases in which vapor covered all or most of the TTC at $\mathrm{ONB}$ (e.g., $\mathrm{HD}$ and $\mathrm{SW}$ at $400 \mathrm{~kg} / \mathrm{m}^{2}-\mathrm{s}$ ); in other instances, vapor partially covered the TTC until the heat flux was increased further, resulting in a gradual increase in the average HTC (e.g., $\mathrm{HU}$ and VU at $400 \mathrm{~kg} / \mathrm{m}^{2}$-s). The lack of clear trends in the heat flux at ONB suggests that orientation does not play a dominant role in this regard.

In general, after ONB, the HTCs increase with increasing heat flux, as expected during nucleate boiling. As CHF is approached, the HTCs plateau or drop, and further increases in the heat flux result in an overtemperature event and power is removed from the TTC. The two-phase HTCs were compared across orientations by dividing the minimum HTC by the maximum HTC at each nominal heat flux common to all orientations. Only data for which all orientations showed two-phase flow were considered and non-linear data near CHF were excluded. The average variation in two-phase HTC between the best and worst orientations decreased considerably as the mass flux increased from $100 \mathrm{~kg} / \mathrm{m}^{2}$-s $(34 \%)$ to $200 \mathrm{~kg} / \mathrm{m}^{2}$-s $(15 \%), 300 \mathrm{~kg} / \mathrm{m}^{2}-\mathrm{s}$ (13\%), $400 \mathrm{~kg} / \mathrm{m}^{2}-\mathrm{s}(11 \%), 600 \mathrm{~kg} / \mathrm{m}^{2}-\mathrm{s}(4 \%)$, and $700 \mathrm{~kg} / \mathrm{m}^{2}-\mathrm{s}$ (8\%). Within each mass flux, the variation decreased as the heat flux increased. For example, at $300 \mathrm{~kg} / \mathrm{m}^{2}$-s, the variation across orientations at $74 \mathrm{~kW} / \mathrm{m}^{2}$ was $17 \%$, but the variation at 152 $\mathrm{kW} / \mathrm{m}^{2}$ was only $11 \%$; at $400 \mathrm{~kg} / \mathrm{m}^{2}-\mathrm{s}$, the variation across orientations at the same heat fluxes decreased from $15 \%$ to $8 \%$. The variation of the HTC with heat flux is less pronounced at mass fluxes of 600 and $700 \mathrm{~kg} / \mathrm{m}^{2}-\mathrm{s}$.

At the lowest mass flux of $100 \mathrm{~kg} / \mathrm{m}^{2}-\mathrm{s}$, the HTCs in the VD orientation are much lower than those in the other orientations. In this orientation and mass flux, the centerline of the channel is largely devoid of liquid and most of the two-phase flow occurs near the channel sides, as shown in Figure 6. The SW orientation provided low HTCs at low heat fluxes; the images show strong gravity effects in this orientation, with a large vapor patch covering the top of the channel and growing toward the channel outlet. The vapor slugs in the vertical upflow orientation are smallest, which can be attributed to gravity accelerating their exit from the channel, which enhances heat transfer and delays $\mathrm{CHF}$.

As the mass flux was increased to 200 and then $300 \mathrm{~kg} / \mathrm{m}^{2}-\mathrm{s}$, better agreement is observed among the five orientations, but some variations in the HTCs persist. For example, at $300 \mathrm{~kg} / \mathrm{m}^{2}-$ $\mathrm{s}$ the VU orientation provides markedly better HTCs at heat fluxes exceeding $150 \mathrm{~kW} / \mathrm{m}^{2}$. Despite some variation in the HTCs, the flow regimes are more consistent across orientations in this range of mass and heat fluxes, as shown in Figure 7. Strong gravity effects on the two-phase flow behavior, which were particularly noticeable in the VD and SW orientations at lower heat and mass fluxes, are largely eliminated.
At and above $400 \mathrm{~kg} / \mathrm{m}^{2}$-s, the HTCs at each heat flux generally agree well across orientations, though the variation still exceeds the experimental uncertainty, indicating a subtle gravity effect. After ONB, the HTCs generally exhibit excellent linearity. The HTCs also show consistent behavior as $\mathrm{CHF}$ is approached and the HTCs plateau or decrease slightly. Although not shown here due to length constraints, images of the twophase flows also showed consistent patterns across orientation at mass fluxes of $600 \mathrm{~kg} / \mathrm{m}^{2}-\mathrm{s}$ and greater.

\section{Dominant Force Regime Maps}

Collectively, the CHF, HTC, and flow regime results suggest that the effect of gravity is small for mass fluxes of $400 \mathrm{~kg} / \mathrm{m}^{2}-\mathrm{s}$ and higher for near-saturated flow boiling of HFE7100 in a 1.01 $\mathrm{mm}$ high by $13.0 \mathrm{~mm}$ wide by $12.7 \mathrm{~mm}$ long channel. In order to compare the results of the present study and those of an earlier study by the present authors [28] with the dominant force regime maps proposed by Reynolds, Saad, and Satterlee [19] and Baba et al. [20], the relevant non-dimensional numbers were calculated via two methods: (1) using the hydraulic diameter for all length scales in Eq. 1-4 and (2) using the channel width for surface tension terms and the channel length in the direction of the gravity vector for gravity terms (subsequently referred to as the HW formulation). All non-dimensional numbers were calculated using liquid only properties; for the maximum outlet quality of 0.088 , which occurred for at a mass flux of $100 \mathrm{~kg} / \mathrm{m}^{2}-\mathrm{s}$, the Weber number increases by $10 \%$ and the Froude number increases by $5 \%$. The results are shown in Figures 11 and 12 .

The formulation of the non-dimensional numbers has a significant effect on the force regime maps. Relative to using the hydraulic diameter as the characteristic length, the HW formulation results in higher Weber numbers, higher Bond numbers for the HU/HD orientations, and much higher Bond numbers for the VU/VD and SW orientations. Similar Bond numbers for the VU/VD and SW orientations result from the channel width (13.0 $\mathrm{mm})$ being close to the channel length $(12.7 \mathrm{~mm})$.

The dominant force regime maps reveal the critical importance of accurately capturing the length scales for the surface tension and gravity terms used in the non-dimensional numbers. For example, using the hydraulic diameter or HW formulations for the HU and HD orientations with the Reynolds, Saad, and Satterlee transitions suggests that only the $100 \mathrm{~kg} / \mathrm{m}^{2}$-s data set for the $1.01 \mathrm{~mm}$ channel would be in the dominated by gravity. However, the same boundaries with the HW formulations for the VU/VD and SW orientations suggest that the data sets captured at or below $400 \mathrm{~kg} / \mathrm{m}^{2}$-s would be dominated by gravity. The current data set showed significant gravity effects at or below $300 \mathrm{~kg} / \mathrm{m}^{2}$-s. This result has important implications for spacecraft thermal management. As noted previously, Kandlikar and Balasubramanian [18] speculated that the absence of gravity would yield two-phase flow behavior similar to that seen in the horizontal orientation, since the absence of gravity would not cause any changes in the forces along the flow direction relative to the horizontal orientation. The dominant force regime maps suggest that inertia-dominated behavior occurs at lower Weber 
numbers for the HU/HD orientations than for the VU/VD and SW orientations. It may therefore be possible that-for microgap channels - the transition to gravity-independent behavior occurs
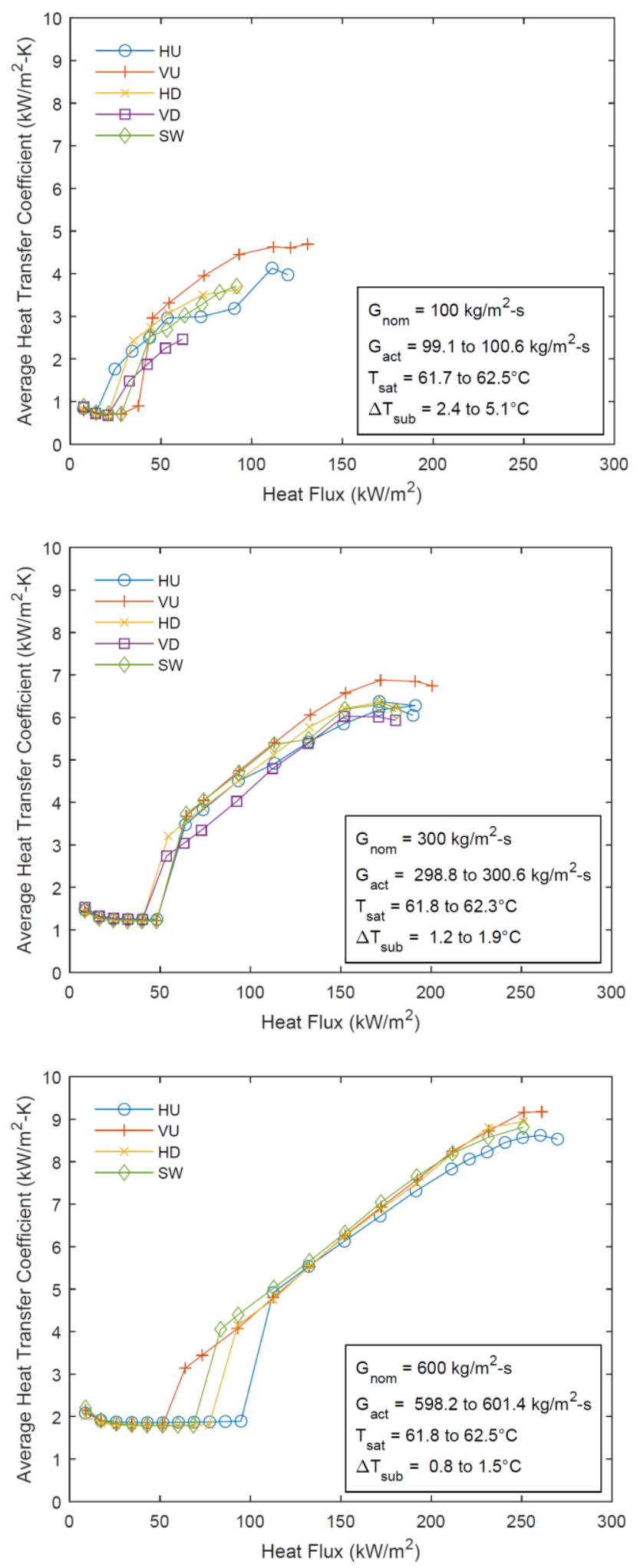

at lower Weber numbers than the transition to orientation-independent behavior. Experimental two-phase data collected in microgravity are required to assess this potential.
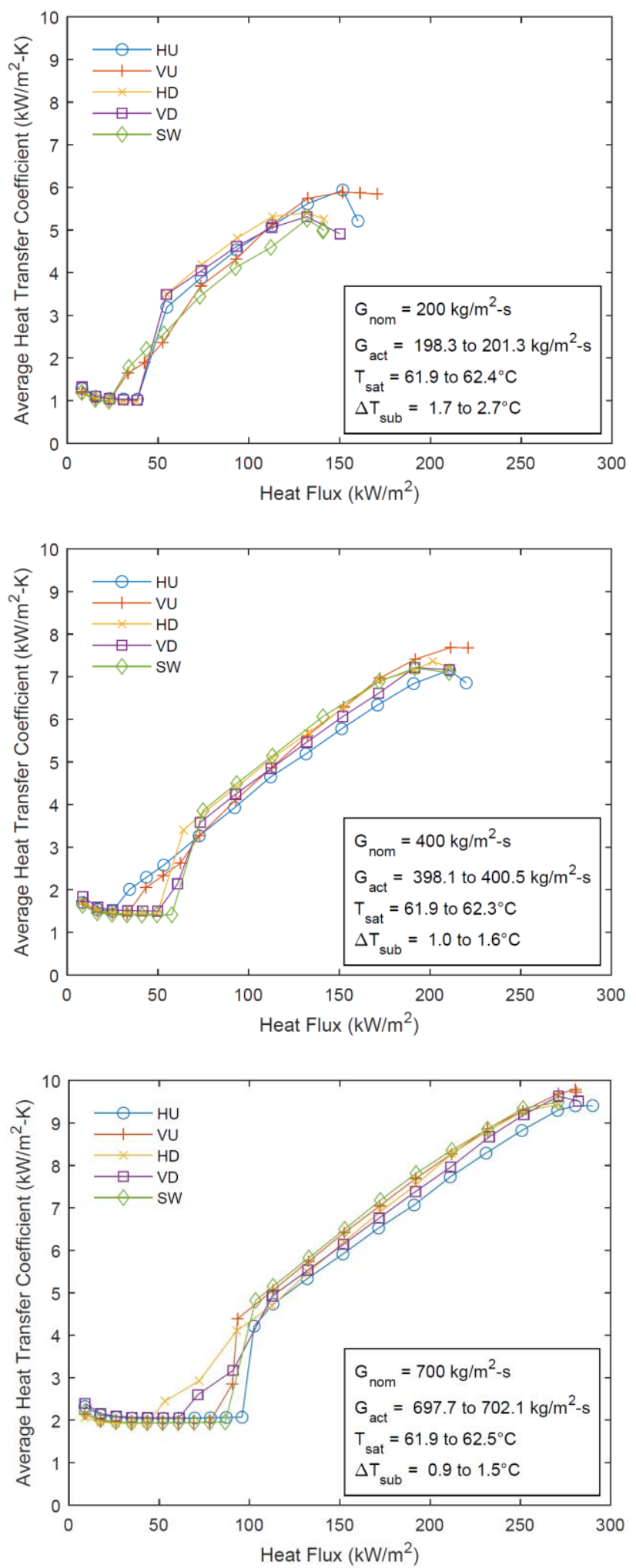

Figure 5: Single- and two-phase heat transfer coefficients as a function of heat flux, evaporator orientation, and mass flux

This material is declared a work of the U.S. Government and is not subject to copyright protection in the United States. Approved for public release; distribution is unlimited. 
Horizontal Heater Up

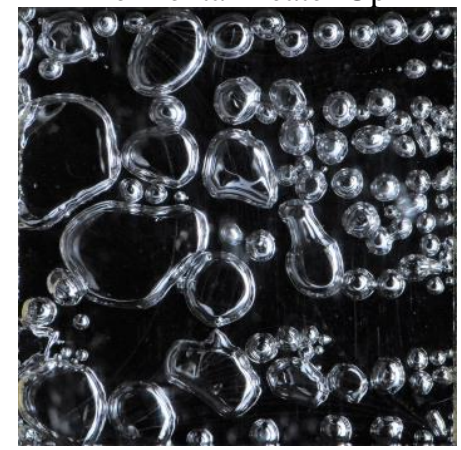

Horizontal Heater Down

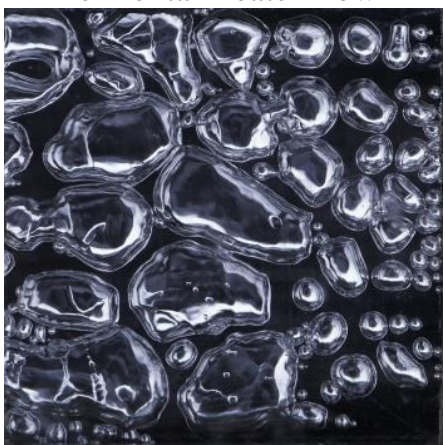

Vertical Upflow

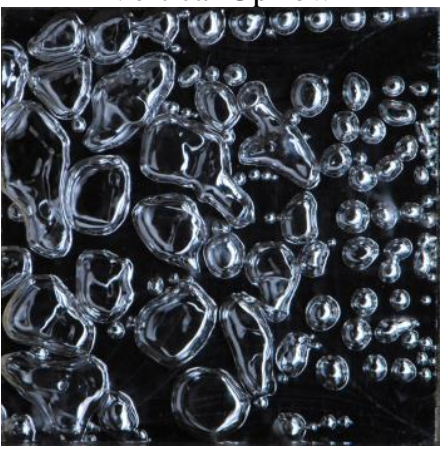

Vertical Downflow

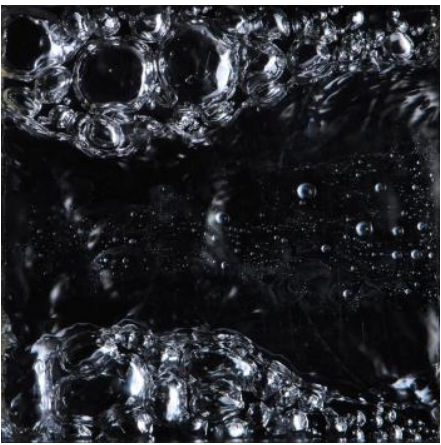

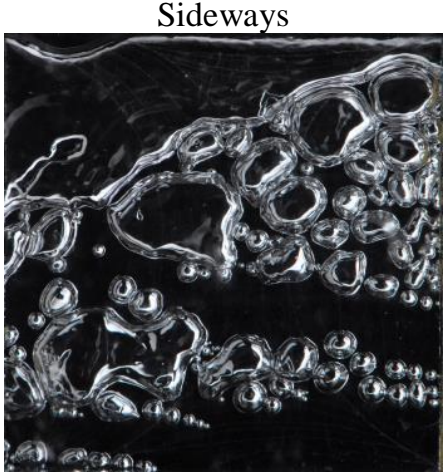

Figure 6: Flow boiling of HFE7100 in a $1.01 \mathrm{~mm}$ by $13.0 \mathrm{~mm}$ channel at mass flux $100 \mathrm{~kg} / \mathrm{m}^{2}$-s and heat flux $53.6 \mathrm{~kW} / \mathrm{m}^{2}$ (flow direction is right to left; see Figure 3 for gravity vector orientation)

Horizontal Heater Up

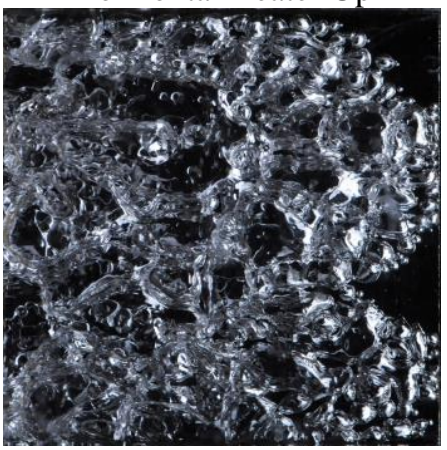

Horizontal Heater Down

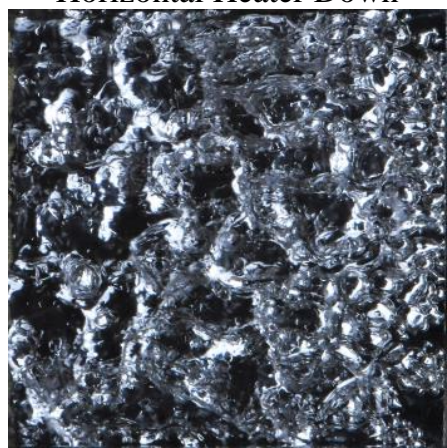

Vertical Upflow
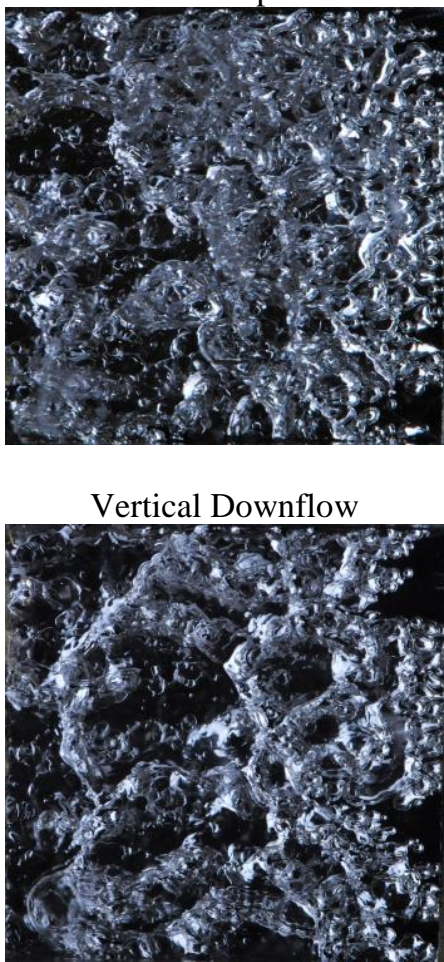

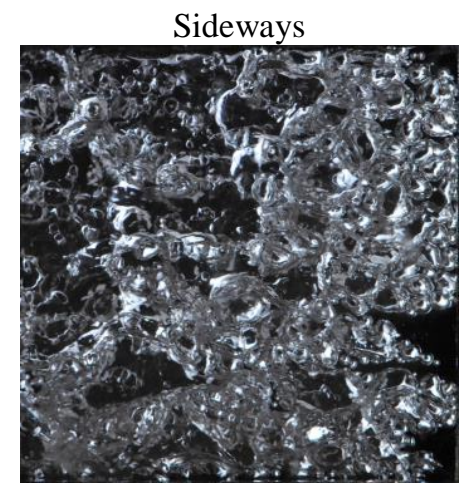

Figure 7: Flow boiling of HFE7100 in a $1.01 \mathrm{~mm}$ by $13.0 \mathrm{~mm}$ channel at mass flux $300 \mathrm{~kg} / \mathrm{m}^{2}-\mathrm{s}$ and heat flux $171.3 \mathrm{~kW} / \mathrm{m}^{2}$ (flow direction is right to left; see Figure 3 for gravity vector orientation)

This material is declared a work of the U.S. Government and is not subject to copyright protection in the United States. Approved for public release; distribution is unlimited. 


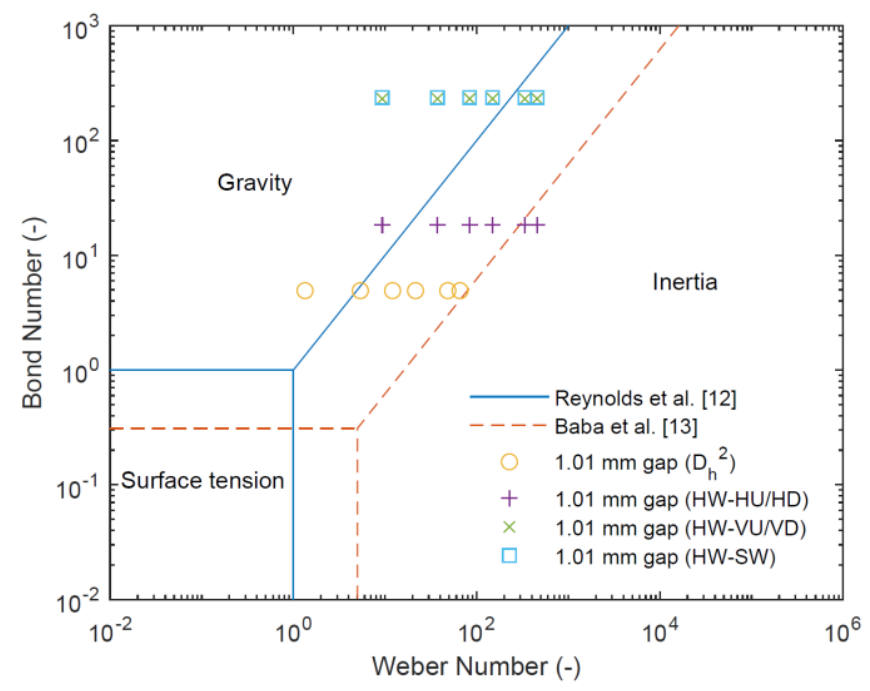

Figure 8: Dominant force maps with boundaries from [19] and [20] with data from present study

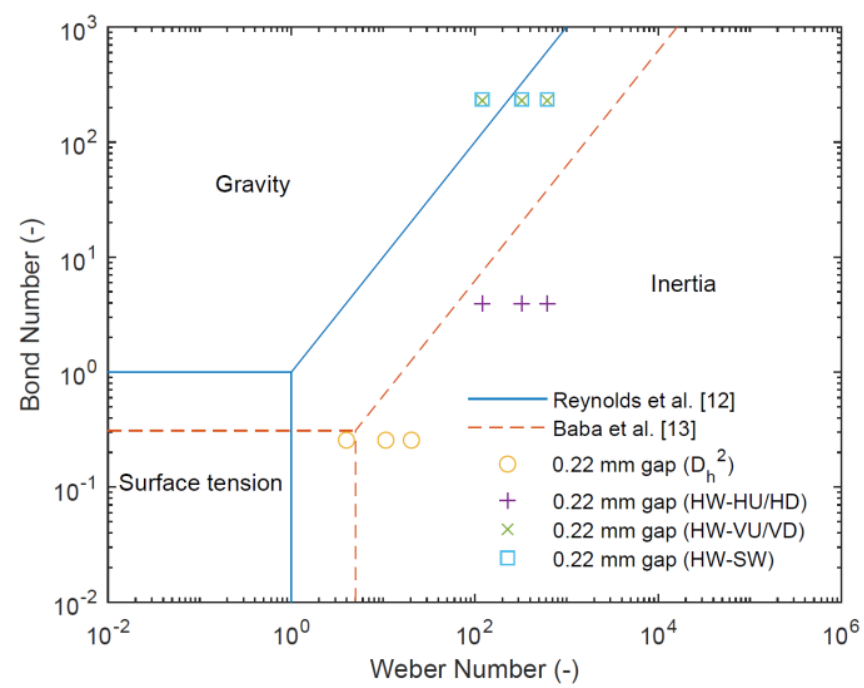

Figure 9: Dominant force maps with boundaries from [19] and [20] with data from [28]

The Reynolds, Saad, and Satterlee transitions correctly predict the regime for five of the six data sets for the $1.01 \mathrm{~mm}$ tall channel and two of the three data sets for the $0.22 \mathrm{~mm}$ tall channel. The Baba et al. transitions fail to predict correctly the regime for any of the nine available data sets. Note that these results are relevant only to the gravity-dominated to inertia-dominated regime boundary, as the Bond number and Weber numbers were well above the threshold values for the surface tension-dominated regime predicted by both groups of researchers.

The present results confirm the utility of dominant force regime maps in predicting the transition to orientation-independent flow boiling, despite much of the work in this area being focused on the Bond number alone (or similar ratios of gravity to surface tension forces) $[10,28]$. Nonetheless, the Bond number must be used - and calculated accurately - to predict the transition from gravity-dominated to inertia-dominated behavior.
As discussed in the "Previous Research" section, there has been considerable research into a $5.0 \mathrm{~mm}$ tall by $2.5 \mathrm{~mm}$ wide channel by other authors [11-13]. The cross sectional area of that channel is similar to the cross sectional area of the channel used for this work $\left(12.5\right.$ versus $\left.13.0 \mathrm{~mm}^{2}\right)$. However, the required mass flux for achieving orientation-independence is very different ( 2400 versus $400 \mathrm{~kg} / \mathrm{m}^{2}$-s), with important implications for pumping power and system efficiency. Additional work is required to clarify whether this behavior is the result of differences in the channel aspect ratio and/or length, or some other factor.

\section{CONCLUSIONS AND FUTURE WORK}

A study has been performed to assess the role of evaporator orientation on two-phase flows in miniature and microscale rectangular ducts of low aspect ratio. Earlier work revealed that many of the criteria proposed for the transition to microscale two-phase flow, which is also the point at which the role of gravity is negligible, could be simplified to constant values of the Bond number. Other researchers have also considered the role of inertia, which has resulted in dominant force maps with regimes for surface tension-, gravity-, and inertia-dominated behavior. The boundaries among the regimes remain a subject of interest.

The orientation-dependence of the two-phase thermofluid behavior of HFE7100 was studied at six mass fluxes covering 100 to $700 \mathrm{~kg} / \mathrm{m}^{2}$-s in a microgap cooler with a height of 1.01 $\mathrm{mm}$, width of $13.0 \mathrm{~mm}$, and length of $12.7 \mathrm{~mm}$. Gravity played a minimal role in the $\mathrm{CHF}$, average HTCs, and flow regimes at and above a mass flux of $400 \mathrm{~kg} / \mathrm{m}^{2}-\mathrm{s}$. These results are in good agreement with the dominant regime map proposed by Reynolds, Saad, and Satterlee [19] using the formulations of the Bond and Weber numbers that account for the surface tension terms scaling with the channel width and the gravity term scaling with the channel length parallel to the gravity vector.

In some previous studies, the Bond number was calculated using the channel hydraulic diameter as the length scale, which resulted in a constant Bond number independent of orientation. The results of the present study suggest that the Bond number can be calculated as intended, with the gravity term scaling with the length parallel to the gravity vector, and the resultant dominant force regimes are predicted accurately. However, questions remain regarding the appropriate length scales used in the calculation of the Bond and Weber numbers for microgap channels. For example, it is unclear whether the use of the channel width for the surface tension term is appropriate, as the liquid-vapor interface rarely spans the channel width. Future studies on experiments with Bond and Weber numbers that span unity would help resolve this issue.

Given the uncertainty in extrapolating orientation-independence to gravity-independence - either or both of which may be required in various applications - a payload incorporating a twophase microgap cooler is under development for planned operation during a suborbital flight. The flow loop will operate during the microgravity $(<0.001 \cdot g)$ and high-g re-entry phases of the flight, which will clarify the role of body forces on two-phase flow regimes and transport rates in microgap channels.

This material is declared a work of the U.S. Government and is not subject to copyright protection in the United States. Approved for public release; distribution is unlimited. 


\section{NOMENCLATURE}

$\begin{array}{cl}\text { Bo } & \text { Bond number }(-) \\ \text { CHF } & \text { Critical heat flux }\left(\mathrm{kW} / \mathrm{m}^{2}\right) \\ D & \text { Diameter }(\mathrm{m}) \\ F r & \text { Froude number }(-) \\ G & \text { Mass flux }\left(\mathrm{kg} / \mathrm{m}^{2}-\mathrm{s}\right) \\ H & \text { Height }(\mathrm{m}) \\ \mathrm{HD} & \text { Horizontal heater facing down } \\ \mathrm{HU} & \text { Horizontal heater facing up } \\ L & \text { Length }(\mathrm{m}) \\ \mathrm{SW} & \text { Sideways } \\ W & \text { Width }(\mathrm{m}) \\ W e & \text { Weber number }(-) \\ U & \text { Velocity (m/s) } \\ \text { VD } & \text { Vertical downflow } \\ \text { VU } & \text { Vertical upflow } \\ g & \text { Acceleration due to gravity }\left(\mathrm{m} / \mathrm{s}^{2}\right)\end{array}$

\section{Subscripts}

$\begin{array}{cl}\text { act } & \text { Actual } \\ l & \text { Liquid } \\ m & \text { Mixture } \\ \text { nom } & \text { Nominal } \\ \text { sat } & \text { Saturation } \\ \text { sub } & \text { Subcooling } \\ v & \text { Vapor }\end{array}$

\section{Greek Letters}

$\begin{array}{ll}\Delta & \text { Differential } \\ \theta & \text { Angle }\left({ }^{\circ}\right) \\ \rho & \text { Density }\left(\mathrm{kg} / \mathrm{m}^{3}\right) \\ \sigma & \text { Surface tension }(\mathrm{N} / \mathrm{m})\end{array}$

\section{ACKNOWLEDGEMENTS}

The authors gratefully acknowledge support from the NASA Center Innovation Fund and Study Fellowship Program, and significant technical contributions and test support from Lucia House, Keith Coulson, and Mario Martins.

\section{REFERENCES}

[1] Bar-Cohen, Avram, Robinson, Franklin, and Deisenroth, David. "Challenges and Opportunities in Gen3 Embedded Cooling with High-Quality Microgap Flow." Proceedings of the International Conference on Electronics Packaging and iMAPS All Asia Conference. Kuwana, Mie, Japan. April 17-21, 2018.

[2] Bar-Cohen, Avram. "Towards Embedded Cooling - Gen 3 Thermal Packaging Technology." Encyclopedia of Thermal Packaging. World Scientific Publishing Company, Hackensack (2014): pp. 367-398.

[3] Bar-Cohen, Avram. "Gen-3 Thermal Management Technology: Role of Microchannels and Nanostructures in an Embedded Cooling Paradigm." Journal of Nanotechnology in Engineering and Medicine Vol. 4 No. 2 (2013): pp.
020907-1-020907-3. DOI $\quad$ DO.1115/1.4023898. http://nanoengineeringmedical.asmedigitalcollection.asme.org/article.aspx? articleid=1764472.

[4] Nakayama, Wataru. "Evolution of Hardware Morphology of Large-Scale Computers and the Trend of Space Allocation for Thermal Management." ASME Journal of Electronic Packaging Vol. 139 (2017): pp. 010801-1010801-22. DOI 10.1115/1.4035019. http://electronicpackaging.asmedigitalcollection.asme.org/article.aspx?articleid $=2575739$.

[5] Swanson, Theodore and Motil, Brian. "NASA Technology Roadmaps TA 14: Thermal Management Systems." (2015). https://www.nasa.gov/sites/default/files/at-

oms/files/2015_nasa_technology_roadmaps_ta_14_thermal _management_final.pdf.

[6] Sunada, Eric, Bhandari, Pradeep, Carroll, Brian, Hendricks, Terry, Furst, Benjamin, Kempenaar, Joshua, Birur, Gajanana, Nagai, Hiroki, Daimaru, Takurou, Sakamoto, Kenichi, Cappucci, Stefano, and Mizerak, Jordan. "A Twophase Mechanically Pumped Fluid Loop for Thermal Control of Deep Space Science Missions." Proceedings of the $46^{\text {th }}$ International Conference on Environmental Systems. ICES-2016-129. Vienna, Austria, July 10-14, 2016.

[7] Alam, Tamanna, Lee, Poh Seng, and Jin, Li-Wen. Flow Boiling in Microgap Channels: Experiment, Visualization, and Analysis. Springer Science \& Business Media, New York (2014)

[8] Kandlikar, Satish. "Scale Effects on Flow Boiling Heat Transfer in Microchannels: A Fundamental Perspective." International Journal of Thermal Sciences Vol. 49 (2010): pp. 1073-1085. DOI 10.1016/j.ijthermalsci.2009.12.016. https://www.sciencedirect.com/science/article/pii/S1290072910000098.

[9] Ullmann, Amos, and Brauner, Neima. "The Prediction of Flow Pattern Maps in Minichannels." Multiphase Science and Technology Vol. 19 No. 1 (2007): pp. 49-73.

[10] Baldassari, Chiara, and Marengo, Marco. "Flow Boiling in Microchannels in Microgravity." Progress in Energy and Combustion Science Vol. 39 (2013): pp. 1-36. DOI 10.1016/j.pecs.2012.10.001. https://www.sciencedirect.com/science/article/pii/S0360128512000585.

[11]Zhang, Hui, Mudawar, Issam, and Hasan, Mohammad. “Application of Flow Boiling for Thermal Management of Electronics in Microgravity and Reduced-Gravity Space Systems." IEEE Transactions on Components and Packaging Technology Vol. 32 No. 2 (2009): pp. 466-477. DOI 10.1109/TCAPT.2008.2004413. https://ieeexplore.ieee.org/document/4745910/.

[12] Konishi, Christopher, Mudawar, Issam, and Hasan, Mohammad. "Investigation of the Influence of Orientation on Critical Heat Flux for Flow Boiling with Two-Phase Inlet." International Journal of Heat and Mass Transfer Vol. 61 (2013): pp. 176-190. DOI 10.1016/j.ijheatmasstransfer.2013.01.076.

https://www.sciencedirect.com/science/article/pii/S0017931013001075.

This material is declared a work of the U.S. Government and is not subject to copyright protection in the United States. Approved for public release; distribution is unlimited. 
[13] Kharangate, Chirag, Konishi, Christopher, and Mudawar, Issam, "Consolidated Methodology to Predicting Flow Boiling Critical Heat Flux for Inclined Channels in Earth Gravity and Microgravity." International Journal of Heat and Mass Transfer Vol. 92 (2016): pp. 467-482. DOI 10.1016/j.ijheatmasstransfer.2015.08.018. https://www.sciencedirect.com/science/article/pii/S0017931015301666.

[14] Wang, Chi-Chuang, Chang, Wen-Jeng, Dai, Chia-Hsing, Lin, Yur-Tsai, and Yang, Kai-Shing. "Effect of Inclination on the Convective Boiling Performance of a Microchannel Heat Sink using HFE-7100." Experimental Thermal and Fluid Science Vol. 36 (2012): pp. 143-148. DOI 10.1016/j.expthermflusci.2011.09.006. https://www.sciencedirect.com/science/article/pii/S0894177711001889.

[15] Lee, Hyoungsoon, Park, Ichung, Mudawar, Issam, and Hasan, Mohammad. "Micro-channel Evaporator for Space Applications - 1. Experimental Pressure Drop and Heat Transfer Results for Different Orientations in Earth Gravity." International Journal of Heat and Mass Transfer Vol. 77 (2014): pp. 1213-1230. DOI 10.1016/j.ijheatmasstransfer.2014.06.012.

https://www.sciencedirect.com/science/article/pii/S0017931014004840.

[16]Zhang, H., Pinjala, D., and Wong, T., "Experimental Characterization of Flow Boiling Heat Dissipation in a Microchannel Heat Sink with Different Orientations." Proceedings of the $7^{\text {th }}$ Electronic Packaging Technology Conference. Grand Copthorne Waterfront, Singapore, December 7-9, 2005. DOI 10.1109/EPTC.2005.1614485. https://ieeexplore.ieee.org/document/1614485/.

[17] Leão, Hugo, Chávez, Cristian, do Nascimento, Francisco, and Ribatski, Gherhardt. "An Analysis of the Effect of the Footprint Orientation on the Thermal-Hydraulic Performance of a Microchannels Heat Sink during Flow Boiling of R245fa." Applied Thermal Engineering Vol. 90 (2015): pp. 907-926. DOI 10.1016/j.applthermaleng.2015.07.043. https://www.sciencedirect.com/science/article/pii/S1359431115007279.

[18] Kandlikar, Satish, and Balasubramanian, Prabhu. "An Experimental Study on the Effect of Gravitation Orientation on Flow Boiling of Water in $1054 \times 197 \mu \mathrm{m}$ Parallel Minichannels," ASME Journal of Heat Transfer Vol. 127 No. 8 (2005): pp. 820-829. DOI 10.1115/1.1928911. http://heattransfer.asmedigitalcollection.asme.org/article.aspx?articlei $\mathrm{d}=1448025$.

[19] Reynolds, William, Saad, Michel, and Satterlee, Hugh. "Capillary Hydrostatics and Hydrodynamics at Low g." Technical Report No. LG-3. Stanford University, Stanford, CA. 1964.

[20] Baba, Soumei, Ohtani, Nobuo, Kawanami, Osamu, Inoue, Koichi, and Ohta, Haruhiko. "Experiments on Dominant Force Regimes in Flow Boiling using Mini-Tubes." Frontiers in Heat and Mass Transfer Vol. 3 (2012): pp. 1-8. DOI 10.5098/hmt.v3.4.3002. http://thermalfluidscentral.org/journals/index.php/Heat_Mass_Transfer/article/vie w/259.
[21] Ohta, Haruhiko, Baba, Atsushi, and Gabriel, Kamiel. "Review of Existing Research on Microgravity Boiling and Two-Phase Flow." Annals of the New York Academy of Sciences Vol. 974 No. 1 (2002): pp. 410-427. DOI 10.1111/j.1749-6632.2002.tb05922.x. https://nyaspubs.onlinelibrary.wiley.com/doi/pdf/10.1111/j.17496632.2002.tb05922.x.

[22] Celata, Gian Piero. "Flow Boiling Heat Transfer in Microgravity: Recent Results." Microgravity Science and Technology Vol. 19 (2007): pp. 13-17. DOI 10.1007/BF02915738. https://link.springer.com/article/10.1007/BF02915738.

[23] Konishi, Christopher, and Mudawar, Issam. "Review of Flow Boiling and Critical Heat Flux in Microgravity" International Journal of Heat and Mass Transfer Vol. 80 (2015): pp. 469-493. DOI 10.1016/j.ijheatmasstransfer.2014.09.017.

https://www.sciencedirect.com/science/article/pii/S0017931014008096.

[24] Chen, Tailian, and Garimella, Suresh. "Effects of Dissolved Air on Subcooled Flow Boiling of a Dielectric Coolant in a Microchannel Heat Sink. ASME Journal of Electronics Packaging Vol. 128 No. 4 (2006): pp. 398-404. DOI 10.1115/1.2351905. http://electronicpackaging.asmedigitalcollection.asme.org/article.aspx? articleID=1408501.

[25] Muller-Steinhagen, H., Epstein, N., and Watkinson, A., "Effect of Dissolved Gases on Subcooled Flow Boiling Heat Transfer." Chemical Engineering and Processing: Process Intensification Vol. 23 No. 2 (1988): pp. 115-124. DOI 10.1016/0255-2701(88)80005-9. https://www.sciencedirect.com/science/article/abs/pii/0255270188800059.

[26] Sawada, Kenichiro, Kurimoto, Takashi, Okamoto, Atsushi, Matsumoto, Satoshi, Asano, Hitoshi, Kawanami, Osamu, Suzuki, Koichi, and Ohta, Haruhiko. "Investigation of Dissolved Air Effects on Subcooled Flow Boiling Heat Transfer for Boiling Two-Phase Flow Experiment aboard ISS." Proceedings of the $44^{\text {th }}$ International Conference on Environmental Systems. Tucson, AZ, July 13-17, 2014.

[27] An, Baolin, Duan, Yuanyuan, Tan, Longshan, and Yang, Zhen. "Vapor Pressure of HFE 7100." Journal of Chemical \& Engineering Data Vol. 60 (2015): pp. 1206-1210. DOI 10.1021/acs.jced.5b00089.

https://pubs.acs.org/doi/abs/10.1021/acs.jced.5b00089.

[28] Robinson, Franklin, and Bar-Cohen, Avram, 2017, "Gravity Effects in Microgap Flow Boiling." Proceedings of the IEEE Intersociety Conference on Thermal and Thermomechanical Phenomena in Electronic Systems. Orlando, FL, May $30 \quad-\quad$ June 2, 2017. DOI 10.1109/ITHERM.2017.7992513. https://ieeexplore.ieee.org/abstract/document/7992513/. 